\title{
Multiple Chronic Conditions and Use of Complementary and Alternative Medicine Among US Adults: Results From the 2012 National Health Interview Survey
}

\author{
Laura Falci, MPH; Zaixing Shi, MS; Heather Greenlee, ND, PhD
}

\begin{abstract}
Suggested citation for this article: Falci L, Shi Z, Greenlee H. Multiple Chronic Conditions and Use of Complementary and Alternative Medicine Among US Adults: Results From the 2012 National Health Interview Survey. Prev Chronic Dis 2016; 13:150501. DOI: http://dx.doi.org/10.5888/pcd13.150501.
\end{abstract}

\section{PEER REVIEWED}

\section{Abstract}

\section{Introduction}

More than $25 \%$ of American adults report having 2 or more chronic conditions. People with chronic conditions often use complementary and alternative medicine (CAM) for self-care and disease management, despite a limited evidence base.

\section{Methods}

Data from the 2012 National Health Interview Survey (NHIS) ( $\mathrm{n}=$ $33,557)$ were analyzed to assess associations between presence of multiple chronic conditions $(\mathrm{n}=13)$ and CAM use, using multivariable relative risk and linear regressions weighted for complex NHIS sampling. CAM use was defined as self-reported use of one or more of 16 therapies in the previous 12 months.

\section{Results}

Chronic conditions were common. US adults reported one (22.3\%) or 2 or more (33.8\%) conditions. Many used at least one form of CAM. Multivitamins, multiminerals, or both $(52.7 \%)$; vitamins (34.8\%); and minerals (28.4\%) were the most common. Compared with adults with no conditions, adults with 2 or more conditions were more likely to use multivitamins or multiminerals or both, vitamins, minerals, nonvitamins or herbs, mind-body therapies, chiropractic or osteopathic manipulation, massage, movement therapies, special diets, acupuncture, naturopathy, or some combination of these therapies $(P<.003)$.

\section{Conclusion}

People with multiple chronic conditions have a high prevalence of CAM use. Longitudinal studies are needed to understand the association between CAM use and chronic disease prevention and treatment.

\section{Introduction}

In 2012, more than $25 \%$ of US adults reported having 2 or more chronic conditions, which increased from $22 \%$ in $2001(1,2)$. Because of this increase, the Department of Health and Human Services (DHHS) formed the Multiple Chronic Conditions Working Group to compile a list of chronic conditions to improve disease management and quality of life for people with chronic comorbid conditions $(3,4)$.

People with multiple chronic conditions face health care burdens because of the complexity of coordinating disease management, including treatment by medical professionals and self-care (3). Prior studies show that people with chronic conditions (5-14) often use complementary and alternative medicine (CAM) therapies as part of disease management. CAM therapies refer to a number of approaches not part of mainstream conventional medicine, used either in complement with or in lieu of standard medical treatments (15). Studies to date suggest that people with chronic conditions are more likely to use CAM, and people with additional conditions have an increased likelihood of overall CAM use $(5,7,8,9,11,16-18)$. However, one study among patients with chronic liver disease showed an inverse association between additional comorbidities and current CAM use (19).

The aim of this study was to determine the association between use of CAM therapies and multiple chronic conditions in a large nationally representative population of US adults. To our knowledge, no studies have examined specific CAM therapy use with comorbid conditions. Studies examining comorbid conditions and 
CAM use have collapsed CAM into any use versus no use, whereas in reality, CAM therapies represent a heterogeneous group of behaviors that differ in type, usage, and bodies of evidence on efficacy. Understanding use of specific CAM modalities among people with multiple chronic conditions could increase knowledge about CAM therapies and disease management.

\section{Methods}

The 2012 National Health Interview Survey (NHIS) (20) is a cross-sectional household survey conducted annually by the Centers for Disease Control and Prevention of the US noninstitutionalized, civilian population. The NHIS uses a complex sampling procedure to obtain a nationally representative sample (21). Since 2002 and every 5 years thereafter, the NHIS has included a survey supplement on CAM use. The 2012 NHIS data set included 34,525 adults (people aged 18 or older). People were excluded from this analysis if they had missing data on all CAM variables $(n=968)$, leaving a final sample size of 33,557 .

The number of chronic conditions was calculated by using the list developed by the Multiple Chronic Conditions Working Group (4). Of the 20 chronic conditions listed by the working group, 13 conditions were ascertained in the NHIS 2012 interview $(4,20)$. The chronic condition variables selected from the 2012 data set were those that best reflected the definition of a chronic condition (4). Participants self-reported having ever been told by a physician they had the following conditions: hypertension 2 times or more, cancer (excluding nonmelanoma skin cancer), chronic obstructive pulmonary disease (COPD, emphysema, or chronic bronchitis in the past 12 months), diabetes, hepatitis, coronary heart disease (CHD), stroke, arthritis, depression, high cholesterol; and any of the following conditions in the past 12 months: asthma attack, weak or failing kidneys, or substance abuse (20). In 2012, because of the CAM supplement being included in the NHIS, additional conditions were assessed that are on the DHHS list but not usually ascertained, including high cholesterol, depression, and substance abuse. A composite variable summed the number of chronic conditions each subject reported (range, 0-13). It was conservatively assumed that any missing value for a single condition would be recoded as a "no" response. The composite variable was categorized into 3 levels: none, 1, and 2 or more of the 13 selected chronic conditions.

The NHIS contains dichotomous (yes/no) information on use of 20 different CAM therapies: body-based therapies including chiropractic or osteopathic manipulation, massage, acupuncture, and movement therapy; mind-body therapies including yoga, tai chi, qi gong, energy healing therapy, hypnosis, and biofeedback; alternative therapies including Ayurvedic medicine, chelation ther- apy, craniosacral therapy, homeopathy, naturopathy, and traditional healing; dietary supplements including vitamins, minerals, multivitamin or multimineral, and other nonvitamin or herbal therapies; and special diets. Energy healing therapy, biofeedback, hypnosis, yoga, tai chi, qi gong, and mind-body therapies such as guided relaxation were collapsed into one mind-body therapy variable because they are similar behavioral CAM therapies. Therefore, this analysis examined 16 dichotomous CAM therapy outcome variables, defined as using a therapy or seeing a practitioner for the modality or both in the past 12 months. A CAM use index was created by summing the number of CAM therapies each individual used (range, 0-16). It was assumed that any missing value for a single therapy would be recoded as a "no" response.

The definition of CAM therapies is largely based on the classifications of the National Center for Complementary and Integrative Health (15), though these analyses also include the use of vitamins, minerals, and multivitamins because of their high prevalence of use. The inclusion of vitamins, minerals, and multivitamins in the definition of CAM varies in the literature. More than $50 \%$ of the US population uses dietary supplements including multivitamins or minerals and singular vitamin and mineral supplements, and this use has increased over the past 20 years (22). Because use is so widespread and the risk for supplements to interact with standard pharmaceutical treatments is high (23), it is important to describe all supplement use. Therefore, we analyzed these individual therapies and 3 CAM indices; all CAM, excluding multivitamins or minerals, and further excluding singular vitamin and mineral supplements.

Demographic and psychosocial characteristics were examined for confounding effects. A priori confounders included respondent-reported race/ethnicity, sex, age, employment status in the previous year (yes/no), imputed family income, and highest level of education. Hypothesized confounders included region, body mass index (BMI), marital status, and the following in the past 12 months: feeling frequently stressed and/or anxious (yes/no), perceived health status (fair or poor vs excellent to good), and fatigue (yes/ no).

Frequencies analysis and bivariable and multivariable analyses were performed to assess the association between the presence of multiple chronic conditions and CAM use. Each CAM therapy was analyzed in separate unadjusted and adjusted Poisson regression models with a robust error variance that estimated the relative risk of CAM use, comparing participants with 1 and 2 or more chronic conditions with participants with no chronic conditions (the reference group). Bonferroni procedures (24) were used to account for multiple comparisons; the standard $\alpha$ level of $5 \%$ was divided by 17 (the total number of specific CAM therapies plus the

\footnotetext{
The opinions expressed by authors contributing to this journal do not necessarily reflect the opinions of the U.S. Department of Health and Human Services, the Public Health Service, the Centers for Disease Control and Prevention, or the authors' affiliated institutions.
} 
CAM index) to create a corrected $\alpha$ level of .003. Data on chelation therapy was not shown because of the small sample size $(\mathrm{n}=$ 17). The relationship between the CAM index and multiple chronic conditions was determined by using a linear regression model adjusted for confounders. Confounders to be included in the final models were identified by using the minimally adjusted models, which included all a priori confounders. Hypothesized confounders were added to minimally adjusted models for all of the separate CAM outcomes. The variables that appreciably changed the parameter estimates by $10 \%$ were included in all of the final models. Multicollinearity of predictors was assessed for the final adjusted models by examining tolerance and variance inflation factor characteristics in a linear regression model (25). Tolerance and variance inflation factors are statistical values that describe the percentage by which 1 predictor is explained by the other predictors in the model. Values of tolerance below $10 \%$ and variance inflation factor above 10 indicate potential collinearity. Missing covariates were not imputed and were excluded from individual regression models. All regression analyses were weighted on the basis of the complex NHIS sampling survey procedure (26), using SAS software version 9.3 (SAS Institute Inc).

\section{Results}

Chronic conditions were common in the US population as sampled in the 2012 NHIS, where $22.3 \%$ of adults reported 1 condition and $33.8 \%$ reported 2 or more conditions; therefore, more than half $(56.1 \%)$ reported at least 1 chronic condition (Table 1$)$. Of the participants with 2 or more chronic conditions, most had 2 conditions $(42.3 \%)$, followed by $3(27.5 \%)$ and $4(15.9 \%)$ conditions (data not shown). The average age of participants was 48 years and most adults were non-Hispanic white (67.2\%), female $(51.8 \%)$, and employed (66.5\%). Compared with adults with no chronic conditions, adults with multiple chronic conditions were older, had a lower income, were less educated, were unemployed, were more likely to be obese, and reported having worse perceived health status and being frequently stressed or anxious.

CAM use was common in the US population. The 4 most frequently used therapies in the past year were multivitamins $(52.7 \%)$, vitamins $(34.8 \%)$, minerals $(28.4 \%)$, and nonvitamin or herbal therapies (17.9\%) (Table 2). Adults with multiple chronic conditions reported using on average 2.0 CAM therapies in the last year. Compared with adults with 1 condition or no chronic conditions, adults with multiple chronic conditions reported higher frequency of multivitamin or multimineral use (57.1\%), vitamins $(42.8 \%)$, minerals $(37.5 \%)$, nonvitamin or herbal therapies $(22.0 \%)$, chiropractic or osteopathic manipulation $(10.1 \%)$, mas- sage $(9.7 \%)$, special diets $(3.6 \%)$, and acupuncture $(1.9 \%)$. Conversely, adults with multiple chronic conditions reported using mind-body and movement therapy less often than those with no chronic conditions or one chronic condition (Table 2).

After controlling for a priori confounders of age, sex, race, family income, employment status, and education, adults with 2 or more chronic conditions were more likely than adults with no chronic conditions to report using multivitamins/minerals, minerals, vitamins, nonvitamin or herbal therapies, mind-body therapies, chiropractic or osteopathic manipulation, massage, and special diets (Table 3 ). In models adjusted for additional confounding factors, the relationships persisted in all outcome models, and the positive association between multiple chronic conditions and use of movement therapy, acupuncture, and naturopathy became significant (Table 3).

For the CAM index, after adjustment, adults with multiple conditions used significantly more CAM therapies than adults with no chronic conditions. No collinearity between predictors was observed for the final adjusted models (data not shown). Sensitivity analyses, examining more conservative definitions of CAM, resulted in smaller $\beta$ coefficients. However, these definitions showed the same overall relationship as the all-inclusive CAM index (Table 3).

\section{Discussion}

Results from the 2012 National Health Interview Survey showed more than half of US adults had at least one chronic condition and over a third had 2 or more chronic conditions. Dietary supplements were used most commonly. In multivariable models we observed that adults with multiple conditions were more likely to report using multiple forms of CAM therapies within the previous 12 months.

Previous studies using the NHIS CAM questionnaire in 2002 and 2007 reported similar associations between specific chronic conditions and CAM use, but no prior analysis has examined use in 13 simultaneous chronic conditions $(6,7,10,11,27)$. In 2002, adults with asthma (7), cancer (6), diabetes (11), and at least one of 5 specific chronic conditions (arthritis, cancer, cardiovascular disease, diabetes, and lung disease) (27) reported higher CAM use than people with no chronic conditions. A study examining both the 2002 and 2007 NHIS data set also found that among adults with diabetes, participants with functional limitations or 3 or more conditions were more likely to use CAM (10). These studies are similar to the results of our analyses, where adults with multiple conditions reported a higher likelihood of CAM use.

The opinions expressed by authors contributing to this journal do not necessarily reflect the opinions of the U.S. Department of Health and Human Services, the Public Health Service, the Centers for Disease Control and Prevention, or the authors' affiliated institutions. 
Our study differs from previously reported NHIS studies in the definition of chronic condition, the definition of CAM, and in the choice of statistical model. First, prior studies vary in their definitions of chronic conditions. Many of these studies examined singular chronic conditions or a limited number of chronic conditions. Our study has an inclusive definition of multiple chronic conditions. Second, our study examines specific CAM therapies as opposed to other studies, which have focused on combined variables for any CAM therapy. Last, previous studies used odds ratios as compared with risk ratios. The epidemiological convention for point estimates states that when prevalence is more than $10 \%$, the odds ratio will show an overestimated measure of association in comparison to the risk ratio, so the risk ratio should be used (28). Risk ratios were used in this analysis because many of the specific CAM therapies were reported as being used by more than $10 \%$ of the population. Although one cannot compare the specific estimates, the general direction of the association is consistent between our analysis and previous analyses. Additionally, these studies report data from the 2002 and 2007 surveys, suggesting this study's results support an ongoing trend of CAM use in association with chronic conditions. To our knowledge, this is the first study to examine the likelihood of specific CAM modality use by multiple chronic conditions as defined by DHHS (4).

A major strength of this study is the examination of CAM use as separate therapies. CAM is a group of separate behaviors that have differing intensity, effectiveness, and adverse effects. When these behaviors are combined into one overall CAM construct, information is lost regarding the direction of effect for specific therapies. Examining specific CAM therapies allowed us to parse out specific self-care and disease management behaviors among adults with chronic conditions. Our results showed that not all CAM therapies are associated with chronic conditions or multiple chronic conditions and further support the decision to examine CAM use as specific therapies rather than one overarching construct.

There are also limitations to note. First, the NHIS is a cross-sectional study, so temporality between chronic conditions and specific CAM use cannot be determined. One possibility is that chronic conditions influence people to use specific CAM therapies. Conversely, it is also possible that the CAM use precedes the development of a chronic condition. Second, there may be selection bias; the NHIS process excludes hospitalized and institutionalized people, causing an underestimation of adults with chronic illnesses as well as the most severe chronic conditions. This selection bias causes the sample to have proportionally more healthy people than are in the US population and more participants that have the ability to access CAM therapies, causing a bias toward the null. Third, both chronic disease status and CAM use is self-reported, resulting in potential misclassification and re- call bias. Lastly, this data set does not include frequency of CAM modality use. If an individual used a modality once in the past year, they would be considered users, as would someone who uses these therapies weekly or daily. This causes an issue of determining what constitutes CAM behaviors. If the users who do not use a modality frequently in truth should be considered nonusers then there is nondifferential misclassification of outcome, biasing the association toward the null. In addition, there may be people with chronic conditions who discontinue CAM within the past year because of factors related to their disease status, which would overestimate the number of regular CAM users.

Multiple chronic conditions increase health care costs not only for the individual but also for the health care system. People with many conditions must navigate the health-care system to coordinate disease management, which often requires regular visits to different medical specialists. This increases the cost for the patient and health-care spending. People with multiple conditions account for approximately $66 \%$ of total health care costs (3). DHHS has created 4 goals to improve factors related to multiple chronic conditions, including changes to the health care system; empowering people with multiple conditions by creating community wellness programs; providing clinicians with education, training, and clinical practice guidelines; and improving research practices to include a focus on comorbid conditions as opposed to specific diseases (29).

Research on CAM use among people with comorbid conditions can provide information in support of the DHHS goals. The high use of dietary supplements among people with comorbid conditions is of major importance in disease management because of potential drug interactions. More research is needed to understand the efficacy of supplements and how they interact with standard chronic condition treatments. In addition, we observed high use of practitioner-based CAM. To improve disease management, an open dialogue between CAM practitioners and medical professionals could help improve decisions on care for patients with multiple chronic conditions. Additional research will help provide clinicians with evidence-based guidelines and lower health-care reimbursements. Therapies with an evidence base for improved health outcomes in this population could also be integrated into community wellness programs.

In summary, using data from a population-based sample of US adults, we found that adults with multiple chronic conditions have an increased likelihood of using specific types of CAM, including dietary supplements, mind-body therapies, chiropractic or osteopathic manipulation, massage, movement therapies, special diets, acupuncture, and naturopathy. Because adults with chronic conditions have an increased likelihood of using specific CAM ther-

The opinions expressed by authors contributing to this journal do not necessarily reflect the opinions of the U.S. Department of Health and Human Services, the Public Health Service, the Centers for Disease Control and Prevention, or the authors' affiliated institutions. 
apies, in the face of unclear evidence, it is important to conduct CAM research on people with multiple chronic conditions and not only populations with specific diseases. Chronic condition management is an integral part in improving mortality and reducing illness among people with chronic conditions. Further research should focus on the efficacy of these therapies in individuals with multiple chronic conditions and on interactions with standard chronic disease treatments.

\section{Acknowledgments}

This research was supported under grant number NIH/NCI K23CA141052, awarded to Dr Heather Greenlee. The funders had no role in the research.

\section{Author Information}

Corresponding Author: Laura Falci, MPH, 722 W. 168th St, 7th Floor, New York, NY 10032. Email: 1sf2120@caa.columbia.edu. Telephone: 212-342-4130.

Author Affiliations: Laura Falci, Zaixing Shi, Department of Epidemiology, Mailman School of Public Health, Columbia University, New York, New York; Heather Greenlee, Department of Epidemiology, Mailman School of Public Health, Columbia University, and Herbert Irving Comprehensive Cancer Center, Columbia University Medical Center, New York, New York.

\section{References}

1. Ward BW, Schiller JS, Goodman RA. Multiple chronic conditions among US adults: a 2012 update. Prev Chronic Dis 2014;11:E62. http://www.cdc.gov/pcd/issues/2014/ 13 0389.htm. Accessed April 4, 2016.

2. Ward BW, Schiller JS. Prevalence of US adults: estimates from the National Health Interview Survey, 2010. Prev Chronic Dis 2013;10:E65. http://www.cdc.gov/pcd/issues/ 2013/12_0203.htm. Accessed April 4, 2016.

3. US Department of Health and Human Services. Multiple chronic conditions - a strategic framework: optimum health and quality of life for individuals with multiple chronic conditions. Washington (DC): US Department of Health and Human Services; 2010. http://www.hhs.gov/ash/initiatives/ mcc/mcc_framework.pdf. Accessed April 4, 2016.
4. Goodman RA, Posner SF, Huang ES, Parekh AK, Koh HK. Defining and measuring chronic conditions: imperatives for research, policy, program, and practice. Prev Chronic Dis 2013;10:E66. http://www.cdc.gov/pcd/issues/2013/ 12_0239.htm. Accessed April 4, 2016.

5. Fouladbakhsh JM, Stommel M. Gender, symptom experience, and use of complementary and alternative medicine practices among cancer survivors in the U.S. cancer population. Oncol Nurs Forum 2010;37(1):E7-15.

6. Mao JJ, Farrar JT, Xie SX, Bowman MA, Armstrong K. Use of complementary and alternative medicine and prayer among a national sample of cancer survivors compared to other populations without cancer. Complement Ther Med 2007; 15(1):21-9.

7. Joubert A, Kidd-Taylor A, Christopher G, Nanda J, Warren R, Lindong I, et al. Complementary and alternative medical practice: self-care preferred vs. practitioner-based care among patients with asthma. J Natl Med Assoc 2010;102(7):562-9.

8. Canaway R, Manderson L. Quality of life, perceptions of health and illness, and complementary therapy use among people with type 2 diabetes and cardiovascular disease. J Altern Complement Med 2013;19(11):882-90.

9. Yeh GY, Davis RB, Phillips RS. Use of complementary therapies in patients with cardiovascular disease. Am J Cardiol 2006;98(5):673-80.

10. Nahin RL, Byrd-Clark D, Stussman BJ, Kalyanaraman N. Disease severity is associated with the use of complementary medicine to treat or manage type- 2 diabetes: data from the 2002 and 2007 National Health Interview Survey. BMC Complement Altern Med 2012;12(1):193.

11. Garrow D, Egede LE. National patterns and correlates of complementary and alternative medicine use in adults with diabetes. J Altern Complement Med 2006;12(9):895-902.

12. Bystritsky A, Hovav S, Sherbourne C, Stein MB, Rose RD, Campbell-Sills L, et al. Use of complementary and alternative medicine in a large sample of anxiety patients. Psychosomatics 2012;53(3):266-72.

13. Richmond JA, Bailey DE, Patel K, Jezsik JA, Muir A, Lin JR, et al. The use of complementary and alternative medicine by patients with chronic hepatitis C. Complement Ther Clin Pract 2010;16(3):124-31.

14. George J, Ioannides-Demos LL, Santamaria NM, Kong DC, Stewart K. Use of complementary and alternative medicines by patients with chronic obstructive pulmonary disease. Med J Aust 2004;181(5):248-51.

The opinions expressed by authors contributing to this journal do not necessarily reflect the opinions of the U.S. Department of Health and Human Services, the Public Health Service, the Centers for Disease Control and Prevention, or the authors' affiliated institutions. 
15. National Center for Complementary and Integrative Health. Complementary, alternative, or integrative health: what's in a name? Bethesda (MD): National Center for Complementary and Integrative Health; 2013. https:/nccih.nih.gov/health/ integrative-health. Accessed April 12, 2016.

16. Carpenter CL, Ganz PA, Bernstein L. Complementary and alternative therapies among very long-term breast cancer survivors. Breast Cancer Res Treat 2009;116(2):387-96.

17. Sirois FM. Provider-based complementary and alternative medicine use among three chronic illness groups: associations with psychosocial factors and concurrent use of conventional health-care services. Complement Ther Med 2008; 16(2):73-80.

18. Jacobson IG, White MR, Smith TC, Smith B, Wells TS, Gackstetter GD, et al.;Millennium Cohort Study Team. Selfreported health symptoms and conditions among complementary and alternative medicine users in a large military cohort. Ann Epidemiol 2009;19(9):613-22.

19. Ferrucci LM, Bell BP, Dhotre KB, Manos MM, Terrault NA, Zaman A, et al. Complementary and alternative medicine use in chronic liver disease patients. J Clin Gastroenterol 2010; 44(2):e40-5.

20. National Health Interview Survey Public-use data file and documentation. Atlanta (GA): Centers for Disease Control and Prevention. http://www.cdc.gov/nchs/nhis/ nhis_2012_data_release.htm. Accessed April 4, 2016.

21. About the National Health Interview Survey. Atlanta (GA): Centers for Disease Control and Prevention. http:// www.cdc.gov/nchs/nhis/about_nhis.htm\#sample_design. Accessed April 4, 2016.

22. Gahche J, Bailey R, Burt V, Hughes J, Yetley E, Dwyer J, et al. Dietary supplement use among US adults has increased since NHANES III (1988-1994). NCHS Data Brief 2011; (61):1-8.

23. National Institutes of Health, Office of Dietary Supplements. Dietary supplements: what you need to know. Bethesda (MD): National Institutes of Health; 2014. https://ods.od.nih.gov/ pubs/DS_WhatYouNeedToKnow.pdf. Accessed April 4, 2016.

24. Kowalski A, Enck P. [Statistical methods: multiple significance tests and the Bonferroni procedure.] Psychother Psychosom Med Psychol 2010;60(7):286-7. German.

25. Belsley DA, Kuh E, Welsch RE. Regression diagnostics: identifying influential data and sources of collinearity. Hoboken (NJ): John Wiley \& Sons; 1980.
26. Centers for Disease Control and Prevention. Variance estimation guidance, NHIS 2006-2012. Atlanta (GA): Centers for Disease Control and Prevention. http:/www.cdc.gov/nchs/ data/nhis/2006var.pdf. Accessed April 4, 2016.

27. Saydah SH, Eberhardt MS. Use of complementary and alternative medicine among adults with chronic diseases: United States 2002. J Altern Complement Med 2006; 12(8):805-12.

28. Rothman KJ, Greenland S, Lash TL. Modern epidemiology. Philadelphia (PA): Lippincott Williams \& Wilkins; 2008.

29. Parekh AK, Kronick R, Tavenner M. Optimizing health for persons with multiple chronic conditions. JAMA 2014; 312(12):1199-200.

\footnotetext{
The opinions expressed by authors contributing to this journal do not necessarily reflect the opinions of the U.S. Department of Health and Human Services, the Public Health Service, the Centers for Disease Control and Prevention, or the authors' affiliated institutions.
} 


\section{Tables}

Table 1. Population Characteristics by Number of Chronic Conditions, National Health Interview Survey, 2012

\begin{tabular}{|c|c|c|c|c|c|c|c|c|c|}
\hline \multirow[b]{3}{*}{ Characteristic } & \multicolumn{8}{|c|}{ No. of Chronic Conditions } & \multirow[b]{3}{*}{$P^{\mathrm{b}}$} \\
\hline & \multicolumn{2}{|c|}{ Total Study Population } & \multicolumn{2}{|c|}{0 Chronic Conditions } & \multicolumn{2}{|c|}{1 Chronic Condition } & \multicolumn{2}{|c|}{$\geq 2$ Chronic Conditions } & \\
\hline & n & $\%(95 \% \mathrm{Cl})^{a}$ & $\mathrm{n}$ & $\%(95 \% \mathrm{Cl})^{\mathrm{a}}$ & $\mathrm{n}$ & $\%(95 \% \mathrm{Cl})^{\mathrm{a}}$ & $\mathrm{n}$ & $\%(95 \% \mathrm{Cl})^{\mathrm{a}}$ & \\
\hline Totals & 33,557 & $100(\mathrm{NA})$ & 13,790 & $\begin{array}{r}43.9 \\
(43.1-44.6)\end{array}$ & 7,427 & $\begin{array}{r}22.3 \\
(21.7-22.9)\end{array}$ & 12,340 & $\begin{array}{r}33.8 \\
(33.1-34.5)\end{array}$ & NA \\
\hline \multicolumn{10}{|l|}{ Race/ethnicity } \\
\hline Hispanic & 5,738 & $\begin{array}{r}15.0 \\
(14.3-15.7) \\
\end{array}$ & 3,155 & $\begin{array}{r}20.0 \\
(18.9-21.0) \\
\end{array}$ & 1,204 & $\begin{array}{r}13.9 \\
(12.9-14.8) \\
\end{array}$ & 1,379 & $\begin{array}{r}9.4 \\
(8.7-10.0) \\
\end{array}$ & \\
\hline Non-Hispanic white & 20,277 & $\begin{array}{r}67.2 \\
(66.3-68.1) \\
\end{array}$ & 7,272 & $\begin{array}{r}59.8 \\
(58.5-61.0)\end{array}$ & 4,711 & $\begin{array}{r}70.1 \\
(68.9-71.4)\end{array}$ & 8,294 & $\begin{array}{r}75.0 \\
(73.9-76.0) \\
\end{array}$ & \\
\hline Non-Hispanic black & 5,101 & $\begin{array}{r}11.8 \\
(11.2-12.3)\end{array}$ & 2,043 & $\begin{array}{r}12.6 \\
(11.9-13.3)\end{array}$ & 1,060 & $\begin{array}{r}10.8 \\
(10.0-11.7)\end{array}$ & 1,998 & $\begin{array}{r}11.3 \\
(10.5-12.1)\end{array}$ & $<.001$ \\
\hline Asian & 2,078 & $5.2(4.9-5.5)$ & 1,164 & $\begin{array}{r}6.9 \\
(6.4-7.5) \\
\end{array}$ & 386 & $4.5(4.0-5.1)$ & 528 & $\begin{array}{r}3.4 \\
(3.0-3.9) \\
\end{array}$ & \\
\hline Other race & 363 & $0.8(0.6-1.0)$ & 156 & $\begin{array}{r}0.8 \\
(0.6-1.0) \\
\end{array}$ & 66 & $0.6(0.4-0.9)$ & 141 & $\begin{array}{r}0.9 \\
(0.7-1.2) \\
\end{array}$ & \\
\hline \multicolumn{10}{|l|}{ Age group, $y$} \\
\hline $18-24$ & 3,329 & $\begin{array}{r}12.9 \\
(12.3-13.5) \\
\end{array}$ & 2,549 & $\begin{array}{r}22.7 \\
(21.6-23.8) \\
\end{array}$ & 590 & $\begin{array}{r}10.1 \\
(9.0-11.1) \\
\end{array}$ & 190 & $\begin{array}{r}2.1 \\
(1.6-2.5) \\
\end{array}$ & \multirow{6}{*}{$<.001$} \\
\hline $25-34$ & 5,955 & $\begin{array}{r}17.6 \\
(17.0-18.2) \\
\end{array}$ & 4,077 & $\begin{array}{r}27.7 \\
(26.8-28.7) \\
\end{array}$ & 1,269 & $\begin{array}{r}16.4 \\
(15.3-17.5)\end{array}$ & 609 & $\begin{array}{r}5.2 \\
(4.7-5.7)\end{array}$ & \\
\hline $35-44$ & 5,611 & $\begin{array}{r}16.9 \\
(16.4-17.5)\end{array}$ & 3,081 & $\begin{array}{r}21.5 \\
(20.6-22.4)\end{array}$ & 1,434 & $\begin{array}{r}19.3 \\
(18.1-20.5)\end{array}$ & 1,096 & $\begin{array}{r}9.4 \\
(8.7-10.1)\end{array}$ & \\
\hline $45-54$ & 5,760 & $\begin{array}{r}18.6 \\
(18.0-19.1) \\
\end{array}$ & 2,105 & $\begin{array}{r}15.8 \\
(15.0-16.6)\end{array}$ & 1,531 & $\begin{array}{r}22.5 \\
(21.3-23.7)\end{array}$ & 2,124 & $\begin{array}{r}19.6 \\
(18.7-20.5)\end{array}$ & \\
\hline $55-64$ & 5,728 & $\begin{array}{r}16.3 \\
(15.8-16.8)\end{array}$ & 1,213 & $\begin{array}{r}7.8 \\
(7.3-8.3)\end{array}$ & 1,304 & $\begin{array}{r}17.4 \\
(16.3-18.6)\end{array}$ & 3,211 & $\begin{array}{r}26.5 \\
(25.3-27.6)\end{array}$ & \\
\hline$\geq 65$ & 7,174 & $\begin{array}{r}17.8 \\
(17.2-18.3)\end{array}$ & 765 & $\begin{array}{r}4.4 \\
(4.0-4.8) \\
\end{array}$ & 1,299 & $\begin{array}{r}14.3 \\
(13.3-15.4) \\
\end{array}$ & 5,110 & $\begin{array}{r}37.3 \\
(36.2-38.4) \\
\end{array}$ & \\
\hline \multicolumn{10}{|l|}{ Sex } \\
\hline Male & 14,858 & $\begin{array}{r}48.2 \\
(47.4-48.9) \\
\end{array}$ & 6,502 & $\begin{array}{r}50.6 \\
(49.5-51.6) \\
\end{array}$ & 3,234 & $\begin{array}{r}47.6 \\
(46.0-49.1) \\
\end{array}$ & 5,122 & $\begin{array}{r}45.5 \\
(44.4-46.6) \\
\end{array}$ & \multirow{2}{*}{$<.001$} \\
\hline Female & 18,699 & $\begin{array}{r}51.8 \\
(51.1-52.6) \\
\end{array}$ & 7,288 & $\begin{array}{r}49.4 \\
(48.4-50.5)\end{array}$ & 4,193 & $\begin{array}{r}52.4 \\
(50.9-54.0)\end{array}$ & 7,218 & $\begin{array}{r}54.5 \\
(53.4-55.6) \\
\end{array}$ & \\
\hline \multicolumn{10}{|l|}{ Marital status } \\
\hline Divorced or separated & 6,305 & $\begin{array}{r}13.5 \\
(13.0-13.9) \\
\end{array}$ & 1,958 & $\begin{array}{r}10.1 \\
(9.6-10.7)\end{array}$ & 1,399 & $\begin{array}{r}13.4 \\
(12.6-14.3)\end{array}$ & 2,948 & $\begin{array}{r}17.8 \\
(17.1-18.6) \\
\end{array}$ & \multirow[b]{2}{*}{$<.001$} \\
\hline Married & 14,583 & $\begin{array}{r}53.2 \\
(52.4-53.9)\end{array}$ & 5,879 & $\begin{array}{r}48.5 \\
(47.4-49.6)\end{array}$ & 3,406 & $\begin{array}{r}56.5 \\
(55.0-58.1)\end{array}$ & 5,298 & $\begin{array}{r}57.0 \\
(55.9-58.2)\end{array}$ & \\
\hline
\end{tabular}

Abbreviations: $\mathrm{Cl}$, confidence interval; NA, not applicable.

${ }^{a}$ Each $\mathrm{n}$ reported in the table is not weighted, but all percentages are weighted.

${ }^{b}$ Rao-Scott $x^{2}$ tests were used to assess associations between population characteristics and number of chronic conditions.

(continued on next page)

The opinions expressed by authors contributing to this journal do not necessarily reflect the opinions of the U.S. Department of Health and Human Services, the Public Health Service, the Centers for Disease Control and Prevention, or the authors' affiliated institutions. 
(continued)

Table 1. Population Characteristics by Number of Chronic Conditions, National Health Interview Survey, 2012

\begin{tabular}{|c|c|c|c|c|c|c|c|c|c|}
\hline \multirow[b]{3}{*}{ Characteristic } & \multicolumn{8}{|c|}{ No. of Chronic Conditions } & \multirow[b]{3}{*}{$P^{\mathrm{b}}$} \\
\hline & \multicolumn{2}{|c|}{ Total Study Population } & \multicolumn{2}{|c|}{0 Chronic Conditions } & \multicolumn{2}{|c|}{1 Chronic Condition } & \multicolumn{2}{|c|}{$\geq 2$ Chronic Conditions } & \\
\hline & $\mathrm{n}$ & $\%(95 \% \mathrm{Cl})^{a}$ & $\mathrm{n}$ & $\%(95 \% \mathrm{Cl})^{a}$ & $\mathrm{n}$ & $\%(95 \% \mathrm{Cl})^{a}$ & $\mathrm{n}$ & $\%(95 \% \mathrm{Cl})^{a}$ & \\
\hline Single & 9,333 & $\begin{array}{r}27.1 \\
(26.4-27.8)\end{array}$ & 5,526 & $\begin{array}{r}39.7 \\
(38.6-40.9)\end{array}$ & 2,009 & $\begin{array}{r}24.9 \\
(23.6-26.1)\end{array}$ & 1,798 & $\begin{array}{r}12.3 \\
(11.6-13.0)\end{array}$ & \\
\hline Widowed & 3,257 & $6.2(5.9-6.5)$ & 389 & $\begin{array}{r}1.7 \\
(1.5-1.9)\end{array}$ & 592 & $5.2(4.6-5.7)$ & 2,276 & $\begin{array}{r}12.8 \\
(12.1-13.5)\end{array}$ & \\
\hline \multicolumn{10}{|l|}{ Region } \\
\hline Northeast & 5,617 & $\begin{array}{r}18.2 \\
(17.5-18.9)\end{array}$ & 2,302 & $\begin{array}{r}18.9 \\
(17.8-19.9)\end{array}$ & 1,292 & $\begin{array}{r}18.9 \\
(17.5-20.2)\end{array}$ & 2023 & $\begin{array}{r}16.9 \\
(16.0-17.8)\end{array}$ & \multirow{4}{*}{$<.001$} \\
\hline Midwest & 6,967 & $\begin{array}{r}22.7 \\
(21.9-23.5)\end{array}$ & 2,783 & $\begin{array}{r}22.0 \\
(21.0-23.1)\end{array}$ & 1,615 & $\begin{array}{r}23.5 \\
(22.1-24.9)\end{array}$ & 2,569 & $\begin{array}{r}23.1 \\
(21.9-24.4)\end{array}$ & \\
\hline South & 12,184 & $\begin{array}{r}36.4 \\
(35.5-37.3)\end{array}$ & 4,848 & $\begin{array}{r}35.2 \\
(34.0-36.4)\end{array}$ & 2,566 & $\begin{array}{r}35.0 \\
(33.5-36.5)\end{array}$ & 4,770 & $\begin{array}{r}38.9 \\
(37.5-40.2)\end{array}$ & \\
\hline West & 8,789 & $\begin{array}{r}22.7 \\
(21.8-23.5)\end{array}$ & 3,857 & $\begin{array}{r}23.9 \\
(22.8-25.0)\end{array}$ & 1,954 & $\begin{array}{r}22.7 \\
(21.3-24.0)\end{array}$ & 2,978 & $\begin{array}{r}21.1 \\
(20.0-22.2)\end{array}$ & \\
\hline \multicolumn{10}{|l|}{ Employment status } \\
\hline Employed & 21,412 & $\begin{array}{r}66.5 \\
(65.7-67.3) \\
\end{array}$ & 10,817 & $\begin{array}{r}78.1 \\
(77.2-79.1) \\
\end{array}$ & 5,235 & $\begin{array}{r}72.4 \\
(71.0-73.9)\end{array}$ & 5,360 & $\begin{array}{r}47.5 \\
(46.3-48.7)\end{array}$ & \multirow{2}{*}{$<.001$} \\
\hline Unemployed & 12,121 & $\begin{array}{r}33.5 \\
(32.7-34.3)\end{array}$ & 2,961 & $\begin{array}{r}21.9 \\
(20.9-22.8)\end{array}$ & 2,188 & $\begin{array}{r}27.6 \\
(26.1-29.0)\end{array}$ & 6,972 & $\begin{array}{r}52.5 \\
(51.3-53.7)\end{array}$ & \\
\hline \multicolumn{10}{|c|}{ Imputed family income, \$ } \\
\hline $0-34,999$ & 13,936 & $\begin{array}{r}33.5 \\
(32.6-34.4)\end{array}$ & 5,376 & $\begin{array}{r}31.7 \\
(30.5-33.0)\end{array}$ & 2,747 & $\begin{array}{r}28.9 \\
(27.4-30.3)\end{array}$ & 5,813 & $\begin{array}{r}38.7 \\
(37.5-40.0)\end{array}$ & \multirow{4}{*}{$<.001$} \\
\hline $35,000-74,999$ & 9,673 & $\begin{array}{r}31.9 \\
(31.2-32.7)\end{array}$ & 4,028 & $\begin{array}{r}31.6 \\
(30.5-32.6)\end{array}$ & 2,193 & $\begin{array}{r}31.8 \\
(30.3-33.2)\end{array}$ & 3,452 & $\begin{array}{r}32.5 \\
(31.3-33.7)\end{array}$ & \\
\hline $75,000-99,999$ & 3,186 & $\begin{array}{r}12.3 \\
(11.8-12.9)\end{array}$ & 1,396 & $\begin{array}{r}12.7 \\
(11.9-13.5)\end{array}$ & 770 & $\begin{array}{r}13.6 \\
(12.5-14.7)\end{array}$ & 1,020 & $\begin{array}{r}11.0 \\
(10.2-11.9)\end{array}$ & \\
\hline$\geq 100,000$ & 4,963 & $\begin{array}{r}22.3 \\
(21.4-23.1)\end{array}$ & 2,252 & $\begin{array}{r}24.0 \\
(22.8-25.2)\end{array}$ & 1,330 & $\begin{array}{r}25.8 \\
(24.2-27.3)\end{array}$ & 1,381 & $\begin{array}{r}17.7 \\
(16.5-18.9)\end{array}$ & \\
\hline \multicolumn{10}{|l|}{ Education } \\
\hline$\leq$ High school diploma & 14,012 & $\begin{array}{r}40.2 \\
(39.4-41.0)\end{array}$ & 5,285 & $\begin{array}{r}37.6 \\
(36.5-38.7)\end{array}$ & 2,876 & $\begin{array}{r}37.6 \\
(36.2-39.0)\end{array}$ & 5,851 & $\begin{array}{r}45.3 \\
(44.0-46.6)\end{array}$ & \multirow{4}{*}{$<.001$} \\
\hline $\begin{array}{l}\text { Some college or } \\
\text { associate degree }\end{array}$ & 10,290 & $\begin{array}{r}31.3 \\
(30.5-32.1)\end{array}$ & 4,288 & $\begin{array}{r}31.7 \\
(30.5-32.8)\end{array}$ & 2,320 & $\begin{array}{r}31.4 \\
(30.1-32.7)\end{array}$ & 3,682 & $\begin{array}{r}30.8 \\
(29.6-31.9) \\
\end{array}$ & \\
\hline Bachelor's degree & 5,838 & $\begin{array}{r}18.5 \\
(17.9-19.0)\end{array}$ & 2,776 & $\begin{array}{r}21.0 \\
(20.1-21.9)\end{array}$ & 1,401 & $\begin{array}{r}19.5 \\
(18.4-20.6)\end{array}$ & 1,661 & $\begin{array}{r}14.5 \\
(13.6-15.3) \\
\end{array}$ & \\
\hline $\begin{array}{l}\text { Graduate or } \\
\text { professional degree }\end{array}$ & 3,282 & $\begin{array}{r}10.0 \\
(9.5-10.5)\end{array}$ & 1,375 & $\begin{array}{r}9.7 \\
(9.0-10.4)\end{array}$ & 811 & $\begin{array}{r}11.5 \\
(10.6-12.4)\end{array}$ & 1,096 & $\begin{array}{r}9.5 \\
(8.7-10.2)\end{array}$ & \\
\hline
\end{tabular}

Abbreviations: $\mathrm{Cl}$, confidence interval; NA, not applicable.

${ }^{a}$ Each $\mathrm{n}$ reported in the table is not weighted, but all percentages are weighted.

${ }^{b}$ Rao-Scott $x^{2}$ tests were used to assess associations between population characteristics and number of chronic conditions.

(continued on next page)

The opinions expressed by authors contributing to this journal do not necessarily reflect the opinions of the U.S. Department of Health and Human Services, the Public Health Service, the Centers for Disease Control and Prevention, or the authors' affiliated institutions. 
(continued)

Table 1. Population Characteristics by Number of Chronic Conditions, National Health Interview Survey, 2012

\begin{tabular}{|c|c|c|c|c|c|c|c|c|c|}
\hline \multirow[b]{3}{*}{ Characteristic } & \multicolumn{8}{|c|}{ No. of Chronic Conditions } & \multirow[b]{3}{*}{$P^{b}$} \\
\hline & \multicolumn{2}{|c|}{ Total Study Population } & \multicolumn{2}{|c|}{0 Chronic Conditions } & \multicolumn{2}{|c|}{1 Chronic Condition } & \multicolumn{2}{|c|}{$\geq 2$ Chronic Conditions } & \\
\hline & $n$ & $\%(95 \% \mathrm{Cl})^{a}$ & $\mathrm{n}$ & $\%(95 \% \mathrm{Cl})^{\mathrm{a}}$ & $\mathrm{n}$ & $\%(95 \% \mathrm{Cl})^{\mathrm{a}}$ & $\mathrm{n}$ & $\%(95 \% \mathrm{Cl})^{a}$ & \\
\hline$<25.0$ & 11,852 & $\begin{array}{r}36.6 \\
(35.9-37.3)\end{array}$ & 6,139 & $\begin{array}{r}46.2 \\
(45.0-47.4)\end{array}$ & 2,597 & $\begin{array}{r}36.1 \\
(34.7-37.5)\end{array}$ & 3,116 & $\begin{array}{r}24.5 \\
(23.6-25.4)\end{array}$ & \multirow{3}{*}{$<.001$} \\
\hline $25.0-29.9$ & 11,268 & $\begin{array}{r}34.9 \\
(34.2-35.6)\end{array}$ & 4,473 & $\begin{array}{r}33.3 \\
(32.2-34.3)\end{array}$ & 2,578 & $\begin{array}{r}35.4 \\
(34.1-36.8)\end{array}$ & 4,217 & $\begin{array}{r}36.5 \\
(35.5-37.6) \\
\end{array}$ & \\
\hline$\geq 30.0$ & 9,434 & $\begin{array}{r}28.5 \\
(27.9-29.2) \\
\end{array}$ & 2,740 & $\begin{array}{r}20.5 \\
(19.6-21.4)\end{array}$ & 2,046 & $\begin{array}{r}28.5 \\
(27.1-29.9) \\
\end{array}$ & 4,648 & $\begin{array}{r}39.0 \\
(37.9-40.1) \\
\end{array}$ & \\
\hline \multicolumn{10}{|c|}{ Perceived health status } \\
\hline Fair or poor & 5,082 & $\begin{array}{r}12.9 \\
(12.4-13.3)\end{array}$ & 565 & $\begin{array}{r}3.5 \\
(3.1-3.8)\end{array}$ & 719 & $8.3(7.6-9.0)$ & 3,798 & $\begin{array}{r}28.1 \\
(27.0-29.2) \\
\end{array}$ & \multirow{2}{*}{$<.001$} \\
\hline Excellent to good & 28,461 & $\begin{array}{r}87.1 \\
(86.7-87.6) \\
\end{array}$ & 1,3221 & $\begin{array}{r}96.5 \\
(96.2-96.9) \\
\end{array}$ & 6,705 & $\begin{array}{r}91.7 \\
(91.0-92.4)\end{array}$ & 8,535 & $\begin{array}{r}71.9 \\
(70.8-73.0) \\
\end{array}$ & \\
\hline \multicolumn{10}{|c|}{ Frequent stress and anxiety } \\
\hline No & 22,690 & $\begin{array}{r}68.3 \\
(67.6-69.0) \\
\end{array}$ & 10,838 & $\begin{array}{r}78.6 \\
(77.6-79.6) \\
\end{array}$ & 4,863 & $\begin{array}{r}64.9 \\
(63.4-66.3)\end{array}$ & 6,989 & $\begin{array}{r}57.2 \\
(56.0-58.5)\end{array}$ & \multirow{2}{*}{$<.001$} \\
\hline Yes & 10,846 & $\begin{array}{r}31.7 \\
(31.0-32.4)\end{array}$ & 2,941 & $\begin{array}{r}21.4 \\
(20.4-22.4) \\
\end{array}$ & 2,562 & $\begin{array}{r}35.1 \\
(33.7-36.6) \\
\end{array}$ & 5,343 & $\begin{array}{r}42.8 \\
(41.5-44.0) \\
\end{array}$ & \\
\hline \multicolumn{10}{|l|}{ Fatigue } \\
\hline No & 28,165 & $\begin{array}{r}84.6 \\
(84.1-85.1)\end{array}$ & 12,986 & $\begin{array}{r}94.1 \\
(93.7-94.6)\end{array}$ & 6,377 & $\begin{array}{r}85.6 \\
(84.5-86.6)\end{array}$ & 8,802 & $\begin{array}{r}71.7 \\
(70.6-72.7) \\
\end{array}$ & \multirow{2}{*}{$<.001$} \\
\hline Yes & 5,374 & $\begin{array}{r}15.4 \\
(14.9-15.9)\end{array}$ & 798 & $\begin{array}{r}5.9 \\
(5.4-6.3)\end{array}$ & 1,049 & $\begin{array}{r}14.4 \\
(13.4-15.5)\end{array}$ & 3,527 & $\begin{array}{r}28.3 \\
(27.3-29.4) \\
\end{array}$ & \\
\hline
\end{tabular}

Abbreviations: $\mathrm{Cl}$, confidence interval; NA, not applicable.

${ }^{\mathrm{a}}$ Each $\mathrm{n}$ reported in the table is not weighted, but all percentages are weighted.

${ }^{\mathrm{b}}$ Rao-Scott $\mathrm{X}^{2}$ tests were used to assess associations between population characteristics and number of chronic conditions. 
Table 2. Use of CAM in the Past 12 Months by Number of Chronic Conditions, National Health Interview Survey, 2012

\begin{tabular}{|c|c|c|c|c|c|c|c|c|c|}
\hline \multirow[b]{2}{*}{ CAM Index, Mean (SE) } & \multicolumn{2}{|c|}{$\begin{array}{l}\text { Total Study Population ( } \mathrm{n} \\
=33,557 \text { ) }\end{array}$} & \multicolumn{2}{|c|}{$\begin{array}{l}0 \text { Chronic Conditions ( } \mathrm{n} \\
=13,790)\end{array}$} & \multicolumn{2}{|c|}{$\begin{array}{l}1 \text { Chronic Condition (n } \\
=7,427 \text { ) }\end{array}$} & \multicolumn{2}{|c|}{$\begin{array}{l}\geq 2 \text { Chronic Conditions ( } \mathrm{n} \\
=12,340 \text { ) }\end{array}$} & \multirow[b]{2}{*}{$P^{\mathrm{b}}$} \\
\hline & Mean $^{a}$ & $95 \% \mathrm{Cl}$ (SE) & Mean $^{a}$ & $95 \% \mathrm{Cl}(\mathrm{SE})$ & Mean $^{a}$ & $95 \% \mathrm{Cl}(\mathrm{SE})$ & Mean $^{a}$ & $95 \% \mathrm{Cl}(\mathrm{SE})$ & \\
\hline All CAM & 1.8 & $1.8-1.8(0.02)$ & 1.5 & $1.5-1.6(0.02)$ & 1.9 & $1.9-2.0(0.03)$ & 2.0 & $2.0-2.1(0.02)$ & $<.001$ \\
\hline Excluding multivitamins & 1.3 & $1.2-1.3(0.01)$ & 1.0 & $1.0-1.1(0.02)$ & 1.4 & $1.3-1.4(0.02)$ & 1.5 & $1.4-1.5(0.02)$ & $<.001$ \\
\hline $\begin{array}{l}\text { Excluding multivitamins, } \\
\text { vitamins and minerals }\end{array}$ & 0.6 & $0.6-0.7(0.01)$ & 0.6 & $0.5-0.6(0.01)$ & 0.7 & $0.7-0.7(0.02)$ & 0.7 & $0.6-0.7(0.02)$ & $<.001$ \\
\hline Specific CAM therapies & $\mathrm{N}$ & $\%(\mathrm{Cl})^{a}$ & $\mathrm{n}$ & $\%(\mathrm{Cl})^{a}$ & $\mathrm{n}$ & $\%(\mathrm{Cl})^{a}$ & $\mathrm{n}$ & $\%(\mathrm{Cl})^{a}$ & $P^{\mathrm{b}}$ \\
\hline $\begin{array}{l}\text { Multivitamin or } \\
\text { multimineral }\end{array}$ & 17,493 & $52.7(52.0-53.5)$ & 6,628 & $\begin{array}{r}48.4 \\
(47.2-49.6) \\
\end{array}$ & 3,985 & $\begin{array}{r}54.6 \\
(53.2-56.0) \\
\end{array}$ & 6,880 & $\begin{array}{r}57.1 \\
(55.9-58.2) \\
\end{array}$ & $<.001$ \\
\hline Vitamin & 11,662 & $34.8(34.0-35.6)$ & 3,751 & $\begin{array}{r}27.6 \\
(26.6-28.6) \\
\end{array}$ & 2,670 & $\begin{array}{r}36.8 \\
(35.3-38.3) \\
\end{array}$ & 5,241 & $\begin{array}{r}42.8(41.5 \\
-44.1) \\
\end{array}$ & $<.001$ \\
\hline Mineral & 9,891 & $28.4(27.7-29.2)$ & 2,979 & $\begin{array}{r}21.0 \\
(20.1-21.9)\end{array}$ & 2,225 & $\begin{array}{r}29.3 \\
(27.9-30.8)\end{array}$ & 4,687 & $\begin{array}{r}37.5(36.3- \\
38.7)\end{array}$ & $<.001$ \\
\hline $\begin{array}{l}\text { Nonvitamin or herbal } \\
\text { therapies }\end{array}$ & 5,974 & $17.9(17.2-18.6)$ & 1,925 & $\begin{array}{r}13.6 \\
(12.8-14.4) \\
\end{array}$ & 1,431 & $\begin{array}{r}20.0 \\
(18.8-21.3) \\
\end{array}$ & 2,618 & $22.0(20.8-23.1$ & $<.001$ \\
\hline Mind-body therapy & 4,127 & $12.5(11.9-13.0)$ & 1,771 & $\begin{array}{r}12.8 \\
(12.1-13.6) \\
\end{array}$ & 1,006 & $\begin{array}{r}13.9 \\
(12.9-15.0) \\
\end{array}$ & 1,350 & $\begin{array}{r}11.0(10.3 \\
-11.7) \\
\end{array}$ & $<.001$ \\
\hline $\begin{array}{l}\text { Chiropractic or osteopathic } \\
\text { manipulation }\end{array}$ & 2,993 & $9.1(8.7-9.5)$ & 991 & $7.5(6.9-8.1)$ & 776 & $\begin{array}{r}10.7 \\
(9.8-11.6) \\
\end{array}$ & 1,226 & $10.1(9.4-10.8)$ & $<.001$ \\
\hline Massage & 2,951 & $8.8(8.4-9.2)$ & 1,094 & $7.8(7.2-8.4)$ & 716 & $9.4(8.6-10.3)$ & 1,141 & $9.7(9.0-10.4)$ & $<.001$ \\
\hline Movement therapy & 2,162 & $6.6(6.2-7.0)$ & 974 & $7.2(6.5-7.8)$ & 584 & $7.8(7.1-8.5)$ & 604 & $5.0(4.5-5.6)$ & $<.001$ \\
\hline Special diets & 1,027 & $3.0(2.8-3.3)$ & 341 & $2.4(2.0-2.7)$ & 266 & $3.4(2.9-4.0)$ & 420 & $3.6(3.1-4.1)$ & $<.001$ \\
\hline Homeopathy & 718 & $2.2(2.0-2.4)$ & 270 & $2.1(1.8-2.4)$ & 185 & $2.6(2.1-3.1)$ & 263 & $2.1(1.8-2.5)$ & .1 \\
\hline Acupuncture & 604 & $1.6(1.4-1.8)$ & 196 & $1.3(1.1-1.5)$ & 142 & $1.8(1.4-2.1)$ & 266 & $1.9(1.6-2.2)$ & .002 \\
\hline Naturopathy & 276 & $0.7(0.6-0.8)$ & 96 & $0.6(0.5-0.8)$ & 75 & $0.7(0.5-1.0)$ & 105 & $0.9(0.7-1.0)$ & .15 \\
\hline Traditional healing & 170 & $0.4(0.4-0.5)$ & 67 & $0.5(0.3-0.6)$ & 35 & $0.4(0.2-0.5)$ & 68 & $0.5(0.3-0.6)$ & .70 \\
\hline Craniosacral therapy & 109 & $0.3(0.2-0.4)$ & 37 & $0.3(0.2-0.4)$ & 25 & $0.2(0.1-0.3)$ & 47 & $0.3(0.2-0.5)$ & .50 \\
\hline Ayurvedic medicine & 96 & $0.3(0.2-0.3)$ & 45 & $0.3(0.2-0.5)$ & 25 & $0.2(0.1-0.3)$ & 26 & $0.2(0.1-0.3)$ & .10 \\
\hline
\end{tabular}

Abbreviations: CAM, complementary and alternative medicine; $\mathrm{Cl}$, confidence interval; SE, standard error.

${ }^{a}$ Each $\mathrm{n}$ reported in the table is not weighted, but all averages and percentages are weighted.

${ }^{\mathrm{b}} P$ values for association between CAM therapies and number of chronic conditions. Rai-Scott $x^{2}$ tests and univariable linear regression models used for categorical and continuous variables, respectively.

The opinions expressed by authors contributing to this journal do not necessarily reflect the opinions of the U.S. Department of Health and Human Services, the Public Health Service, the Centers for Disease Control and Prevention, or the authors' affiliated institutions. 
Table 3. Association Between CAM Use and Number of Chronic Conditions, National Health Interview Survey, 2012

\begin{tabular}{|c|c|c|c|c|c|c|c|c|}
\hline \multicolumn{9}{|c|}{ CAM Modality Outcome Measures ${ }^{a}$} \\
\hline \multicolumn{3}{|c|}{ Unadjusted Models } & \multicolumn{3}{|c|}{ Minimally Adjusted ${ }^{b}$ Models } & \multicolumn{3}{|c|}{ Final Adjusted ${ }^{c}$ Models } \\
\hline \multicolumn{3}{|c|}{ No. of Chronic Conditions } & \multicolumn{3}{|c|}{ No. of Chronic Conditions } & \multicolumn{3}{|c|}{ No. of Chronic Conditions } \\
\hline 0 & 1 & $\geq 2$ & 0 & 1 & $\geq 2$ & 0 & 1 & $\geq 2$ \\
\hline$n=13,790$ & $n=7,427$ & $n=12,340$ & $n=13,790$ & $n=7,427$ & $n=12,340$ & $n=13,790$ & $n=7,427$ & $N=12,340$ \\
\hline \multicolumn{9}{|c|}{ CAM indexes, $\beta$ coefficient $(95 \% \mathrm{Cl})^{\mathrm{d}}$} \\
\hline \multicolumn{9}{|l|}{ All CAM } \\
\hline \multirow[t]{2}{*}{ Ref } & $0.4^{\mathrm{e}}$ & $0.5^{\mathrm{e}}$ & \multirow[t]{2}{*}{ Ref } & $0.3^{\mathrm{e}}$ & $0.6^{\mathrm{e}}$ & \multirow[t]{2}{*}{ Ref } & $0.3^{\mathrm{e}}$ & $0.6^{\mathrm{e}}$ \\
\hline & $(0.3-0.4)$ & $(0.5-0.6)$ & & $(0.3-0.4)$ & $(0.5-0.6)$ & & $(0.3-0.4)$ & $(0.6-0.7)$ \\
\hline
\end{tabular}

Excluding multivitamins/minerals

\begin{tabular}{r|r|r}
\multirow{2}{*}{ Ref } & $0.3^{\mathrm{e}}$ & $0.4^{\mathrm{e}}$ \\
\cline { 2 - 3 } & $(0.3-0.4)$ & $(0.4-0.5)$ \\
\hline
\end{tabular}

\begin{tabular}{r|r|r|}
\hline \multirow{R}{*}{$\operatorname{0ef}$} & $0.3^{\mathrm{e}}$ & $0.5^{\mathrm{e}}$ \\
\cline { 2 - 3 } & $(0.2-0.3)$ & $(0.4-0.5)$ \\
\hline
\end{tabular}

$\operatorname{Ref} \mid \begin{array}{r}0.3^{\mathrm{e}} \\$\cline { 2 - 2 }$(0.2-0.3) \\ \hline\end{array}$

Excluding multivitamins, vitamins, and minerals

\begin{tabular}{|r|r|r}
\hline \multirow{2}{*}{$\operatorname{Ref}$} & $0.1^{\mathrm{e}}$ & $0.1^{\mathrm{e}}$ \\
\cline { 2 - 3 } & $(0.1-0.2)$ & $(0.1-0.1)$ \\
\hline
\end{tabular}

\begin{tabular}{r|r|r|}
\hline \multirow{2}{*}{$\operatorname{0ef}$} & $0.1^{\mathrm{e}}$ & $0.2^{\mathrm{e}}$ \\
\cline { 2 - 3 } & $(0.1-0.2)$ & $(0.2-0.2)$ \\
\hline
\end{tabular}

$\operatorname{Ref} \mid$\begin{tabular}{r|}
$0.1^{\mathrm{e}}$ \\
\cline { 2 - 2 }$(0.1-0.2)$ \\
\hline
\end{tabular}

$(0.5-0.6)$

\section{Specific CAM therapies, RR $(95 \% \mathrm{Cl})^{f}$}

Multivitamin or multimineral

\begin{tabular}{r|r|r}
\multirow{2}{*}{ Ref } & $1.1^{\mathrm{e}}$ & $1.2^{\mathrm{e}}$ \\
\cline { 2 - 3 } & $(1.1-1.2)$ & $(1.1-1.2)$ \\
\hline
\end{tabular}

\begin{tabular}{r|r|r|}
\hline \multirow{R}{*}{$1.1^{\mathrm{g}}$} & $1.1^{\mathrm{e}}$ \\
\cline { 2 - 3 } & $(1.0-1.1)$ & $(1.1-1.2)$ \\
\hline
\end{tabular}

\begin{tabular}{r|r}
$\operatorname{Ref}$ & $1.1^{\mathrm{e}}$ \\
\cline { 2 - 2 } & $(1.0-1.1)$ \\
\hline
\end{tabular}

Mineral

\begin{tabular}{r|r|r}
\multirow{2}{*}{ Ref } & $1.4^{\mathrm{e}}$ & 1.8 \\
\cline { 2 - 3 } & $(1.3-1.5)$ & $(1.7-1.9)$ \\
\hline
\end{tabular}

\begin{tabular}{|r|r|r|}
\hline \multirow{2}{*}{$\operatorname{1ef}$} & $1.2^{\mathrm{e}}$ & $1.4^{\mathrm{e}}$ \\
\cline { 2 - 3 } & $(1.1-1.3)$ & $(1.3-1.5)$ \\
\hline
\end{tabular}

$\operatorname{Ref} \mid \begin{array}{r}1.2^{\mathrm{e}} \\$\cline { 2 - 2 }$(1.1-1.3) \\ \hline\end{array}$

Vitamin

\begin{tabular}{r|r|r}
\multirow{2}{*}{$\operatorname{Ref}$} & $1.3^{\mathrm{e}}$ & 1.6 \\
\cline { 2 - 3 } & $(1.3-1.4)$ & $(1.5-1.6$ \\
\hline
\end{tabular}

Ref

\begin{tabular}{l|r|}
$1.2^{\mathrm{e}}$ & $1.4^{\mathrm{e}}$ \\
\hline
\end{tabular}

(1.2-1.3)

$(1.3-1.5)$

Ref

$1.2^{\mathrm{e}}$

$(1.2-1.3)$

$(1.4-1.5)$

Nonvitamin or herbal therapies

\begin{tabular}{r|r|r}
\multirow{2}{*}{ Ref } & $1.5^{\mathrm{e}}$ & $1.6^{\mathrm{e}}$ \\
\cline { 2 - 3 } & $(1.4-1.6)$ & $(1.5-1.7)$
\end{tabular}

Ref

$1.7^{\mathrm{e}}$

(1.3-1.5)

$(1.5-1.8)$

\begin{tabular}{r|r|} 
Ref & $1.4^{\mathrm{e}}$ \\
\cline { 2 - 2 } & $(1.3-1.6)$ \\
\hline
\end{tabular}

$1.7^{\mathrm{e}}$

Mind-body therapy

\begin{tabular}{|r|r|r|r|r|r|}
\multirow{2}{*}{$\operatorname{Ref}$} & $1.1^{\mathrm{h}}$ & $0.9^{\mathrm{e}}$ & $\operatorname{Ref}$ & $1.2^{\mathrm{e}}$ & $1.4^{\mathrm{e}}$ \\
\cline { 2 - 3 } \cline { 5 - 5 } & $(1.0-1.2)$ & $(0.8-0.9)$ & & $(1.1-1.4)$ & $(1.3-1.6)$ \\
\hline
\end{tabular}

Ref \begin{tabular}{r|r|}
$1.3^{\mathrm{e}}$ \\
\cline { 2 - 2 }$(1.2-1.4)$
\end{tabular}

Abbreviations: CAM, complementary and alternative medicine; $\mathrm{Cl}$, confidence interval; $\mathrm{RR}$, relative risk.

${ }^{a}$ Each modality was run as a separate relative risk regression model.

${ }^{\mathrm{b}}$ Adjusted for age, sex, race, income, employment status, and education.

${ }^{c}$ Adjusted for age, sex, race, income, employment status, education, body mass index, and marital status.

${ }^{d}$ Values are $\beta(95 \% \mathrm{Cl})$.

${ }^{\mathrm{e}} P$ value $<.001$ ( $\alpha=.003$ after Bonferroni adjustment for multiple comparisons).

${ }^{\mathrm{f}}$ Values are RR $(95 \% \mathrm{Cl})$.

${ }^{\mathrm{g}} P$ value $<.003(\alpha=.003$ after Bonferroni adjustment for multiple comparisons).

${ }^{\mathrm{h}} P$ value $>.003$ ( $\alpha=.003$ after Bonferroni adjustment for multiple comparisons). 
(continued)

Table 3. Association Between CAM Use and Number of Chronic Conditions, National Health Interview Survey, 2012

\begin{tabular}{|c|c|c|c|c|c|c|c|c|}
\hline \multicolumn{9}{|c|}{ CAM Modality Outcome Measures $^{a}$} \\
\hline \multicolumn{3}{|c|}{ Unadjusted Models } & \multicolumn{3}{|c|}{ Minimally Adjusted ${ }^{\mathrm{b}}$ Models } & \multicolumn{3}{|c|}{ Final Adjusted ${ }^{c}$ Models } \\
\hline \multicolumn{3}{|c|}{ No. of Chronic Conditions } & \multicolumn{3}{|c|}{ No. of Chronic Conditions } & \multicolumn{3}{|c|}{ No. of Chronic Conditions } \\
\hline 0 & 1 & $\geq 2$ & 0 & 1 & $\geq 2$ & 0 & 1 & $\geq 2$ \\
\hline$n=13,790$ & $n=7,427$ & $n=12,340$ & $n=13,790$ & $n=7,427$ & $n=12,340$ & $n=13,790$ & $n=7,427$ & $N=12,340$ \\
\hline
\end{tabular}

Chiropractic or osteopathic manipulation

\begin{tabular}{|r|r|r|r|r|r|}
\hline Ref & $1.4^{\mathrm{e}}$ & $1.3^{\mathrm{e}}$ & Ref & $1.3^{\mathrm{e}}$ & $1.4^{\mathrm{e}}$ \\
\cline { 2 - 5 } & $(1.3-1.6)$ & $(1.2-1.5)$ & & $(1.2-1.5)$ & $(1.2-1.6)$ \\
\hline
\end{tabular}

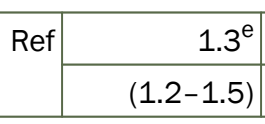

Ref

Massage

\begin{tabular}{r|r|r} 
Ref & $1.2^{\mathrm{g}}$ & $1.2^{\mathrm{e}}$ \\
\cline { 2 - 3 } & $(1.1-1.4)$ & $(1.1-1.4)$ \\
\hline
\end{tabular}

\begin{tabular}{r|r|r|}
\hline \multirow{R}{*}{$\operatorname{1.}$} & $1.3^{\mathrm{e}}$ & $1.8^{\mathrm{e}}$ \\
\cline { 2 - 3 } & $(1.1-1.4)$ & $(1.6-2.1)$ \\
\hline
\end{tabular}

Ref

\begin{tabular}{r|r|}
$1.3^{\mathrm{e}}$ \\
\hline$(1.2-1.5)$
\end{tabular}

Ref

$1.2^{\mathrm{h}}$

(1.1-1.4)

$\operatorname{Ref} \mid$\begin{tabular}{r|}
$1.3^{\mathrm{e}}$ \\
\cline { 2 - 3 }$(1.1-1.4)$
\end{tabular}

$1.3^{\mathrm{e}}$

(1.1-1.5)

\begin{tabular}{r|r|r|}
\hline $\operatorname{Ref}$ & $1.5^{\mathrm{e}}$ & $1.9^{\mathrm{e}}$ \\
\cline { 2 - 3 } & $(1.2-1.9)$ & $(1.5-2.4)$ \\
\hline
\end{tabular}

(1.3-1.8)

(1.2-1.8)

Homeopathy

\begin{tabular}{r|r|r}
\multirow{2}{*}{ Ref } & $1.2^{\mathrm{h}}$ & $1.0^{\mathrm{h}}$ \\
\cline { 2 - 3 } & $(1.0-1.6)$ & $(0.8-1.3)$ \\
\hline
\end{tabular}

Acupuncture

\begin{tabular}{r|r|r} 
Ref & $1.4^{\mathrm{h}}$ & $1.5^{\mathrm{e}}$ \\
\cline { 2 - 3 } & $(1.0-1.8)$ & $(1.2-1.9)$ \\
\hline
\end{tabular}

Naturopathy

\begin{tabular}{r|r|r|} 
Ref & $1.2^{\mathrm{h}}$ & $1.4^{\mathrm{h}}$ \\
\cline { 2 - 3 } & $(0.9-1.8)$ & $(1.0-2.0)$ \\
\hline
\end{tabular}

Ref

$1.3^{h}$

$1.3^{h}$
$(1.0-1.7)$

\begin{tabular}{r|r|r|} 
Ref & $1.3^{\mathrm{h}}$ & $1.6^{\mathrm{h}}$ \\
\cline { 2 - 3 } & $(1.0-1.8)$ & $(1.2-2.1)$ \\
\hline
\end{tabular}

Ref \begin{tabular}{r|r}
$1.5^{\mathrm{e}}$ \\
\cline { 2 - 2 } & $(1.2-1.9)$ \\
\hline
\end{tabular}

(1.2-1.6)

Ref

(1.0-1.8)

(1.2-1.9)

.9)

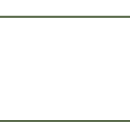

\begin{tabular}{r|r|r|}
\hline \multirow{2}{*}{$\operatorname{lef}$} & $1.3^{\mathrm{h}}$ & $2.0^{\mathrm{h}}$ \\
\cline { 2 - 3 } & $(0.9-2.0)$ & $(1.3-3.2)$ \\
\hline
\end{tabular}

7)

$\operatorname{Ref} \mid$\begin{tabular}{r}
$1.3^{\mathrm{h}}$ \\
\cline { 2 - 2 }
\end{tabular}

\begin{tabular}{|r|r|r|}
\multirow{2}{*}{ Ref } & $1.3^{\mathrm{h}}$ & $1.8^{\mathrm{e}}$ \\
\cline { 2 - 3 } & $(1.0-1.8)$ & $(1.3-2.4)$ \\
\hline
\end{tabular}

(1.0-1.8)

(1.5-2.4)

$18^{\mathrm{e}}$

Traditional healers

\begin{tabular}{|c|c|c|c|c|c|c|c|c|}
\hline \multirow[t]{2}{*}{ Ref } & $0.8^{\mathrm{h}}$ & $1.0^{\mathrm{h}}$ & \multirow[t]{2}{*}{ Ref } & $1.1^{\mathrm{h}}$ & $1.9^{\mathrm{h}}$ & \multirow[t]{2}{*}{ Ref } & $1.1^{\mathrm{h}}$ & $1.9^{\mathrm{h}}$ \\
\hline & $(0.5-1.3)$ & $(0.6-1.5)$ & & $(0.6-1.9)$ & $(1.1-3.2)$ & & $(0.6-2.0)$ & $(1.1-3.2)$ \\
\hline
\end{tabular}

\begin{tabular}{|c|c|c|c|c|c|c|c|c|}
\hline \multirow[t]{2}{*}{ Ref } & $0.8^{\mathrm{h}}$ & $1.0^{\mathrm{h}}$ & \multirow[t]{2}{*}{ Ref } & $1.1^{\mathrm{h}}$ & $1.9^{\mathrm{h}}$ & \multirow[t]{2}{*}{ Ref } & $1.1^{\mathrm{h}}$ & $1.9^{\mathrm{h}}$ \\
\hline & $(0.5-1.3)$ & $(0.6-1.5)$ & & $(0.6-1.9)$ & $(1.1-3.2)$ & & $(0.6-2.0)$ & $(1.1-3.2)$ \\
\hline
\end{tabular}

Ref

\begin{tabular}{r|r|}
\hline $1.4^{\mathrm{h}}$ \\
\hline$(0.9-2.1)$
\end{tabular}

\begin{tabular}{|r|r|}
\hline $4^{h}$ & $2.4^{e}$ \\
\hline 1$)$ & $(1.5-3.8)$ \\
\hline
\end{tabular}

Abbreviations: CAM, complementary and alternative medicine; Cl, confidence interval; RR, relative risk.

${ }^{a}$ Each modality was run as a separate relative risk regression model.

${ }^{\mathrm{b}}$ Adjusted for age, sex, race, income, employment status, and education.

${ }^{c}$ Adjusted for age, sex, race, income, employment status, education, body mass index, and marital status.

${ }^{d}$ Values are $\beta(95 \% \mathrm{Cl})$.

${ }^{\mathrm{e}} P$ value $<.001$ ( $\alpha=.003$ after Bonferroni adjustment for multiple comparisons).

${ }^{f}$ Values are RR $(95 \% \mathrm{Cl})$.

${ }^{g} P$ value $<.003$ ( $\alpha=.003$ after Bonferroni adjustment for multiple comparisons).

${ }^{\mathrm{h}} P$ value $>.003$ ( $\alpha=.003$ after Bonferroni adjustment for multiple comparisons).

(continued on next page)

\footnotetext{
The opinions expressed by authors contributing to this journal do not necessarily reflect the opinions of the U.S. Department of Health and Human Services, the Public Health Service, the Centers for Disease Control and Prevention, or the authors' affiliated institutions.
}

12 Centers for Disease Control and Prevention • www.cdc.gov/pcd/issues/2016/15_0501.htm 
(continued)

Table 3. Association Between CAM Use and Number of Chronic Conditions, National Health Interview Survey, 2012

\begin{tabular}{|c|c|c|c|c|c|c|c|c|}
\hline \multicolumn{9}{|c|}{ CAM Modality Outcome Measures ${ }^{a}$} \\
\hline \multicolumn{3}{|c|}{ Unadjusted Models } & \multicolumn{3}{|c|}{ Minimally Adjusted ${ }^{b}$ Models } & \multicolumn{3}{|c|}{ Final Adjusted ${ }^{c}$ Models } \\
\hline \multicolumn{3}{|c|}{ No. of Chronic Conditions } & \multicolumn{3}{|c|}{ No. of Chronic Conditions } & \multicolumn{3}{|c|}{ No. of Chronic Conditions } \\
\hline 0 & 1 & $\geq 2$ & 0 & 1 & $\geq 2$ & 0 & 1 & $\geq 2$ \\
\hline$n=13,790$ & $n=7,427$ & $n=12,340$ & $n=13,790$ & $n=7,427$ & $n=12,340$ & $n=13,790$ & $n=7,427$ & $N=12,340$ \\
\hline \multirow[t]{2}{*}{ Ref } & $0.8^{\mathrm{h}}$ & $1.2^{\mathrm{h}}$ & \multirow[t]{2}{*}{ Ref } & $0.7^{\mathrm{h}}$ & $1.2^{h}$ & \multirow[t]{2}{*}{ Ref } & $0.7^{\mathrm{h}}$ & $1.4^{\mathrm{h}}$ \\
\hline & $(0.4-1.5)$ & $(0.7-2.0)$ & & $(0.3-1.4)$ & $(0.6-2.7)$ & & $(0.4-1.5)$ & $(0.6-3.1)$ \\
\hline \multicolumn{9}{|c|}{ Ayurvedic medicine } \\
\hline \multirow[t]{2}{*}{ Ref } & $0.7^{\mathrm{h}}$ & $0.5^{\mathrm{h}}$ & \multirow[t]{2}{*}{ Ref } & $0.7^{\mathrm{h}}$ & $0.6^{\mathrm{h}}$ & \multirow[t]{2}{*}{ Ref } & $0.7^{\mathrm{h}}$ & $0.6^{\mathrm{h}}$ \\
\hline & $(0.4-1.2)$ & $(0.3-1.0)$ & & $(0.4-1.2)$ & $(0.3-1.3)$ & & $(0.4-1.3)$ & $(0.3-1.3)$ \\
\hline
\end{tabular}

Abbreviations: CAM, complementary and alternative medicine; $\mathrm{Cl}$, confidence interval; RR, relative risk.

${ }^{a}$ Each modality was run as a separate relative risk regression model.

${ }^{\mathrm{b}}$ Adjusted for age, sex, race, income, employment status, and education.

${ }^{c}$ Adjusted for age, sex, race, income, employment status, education, body mass index, and marital status.

${ }^{\mathrm{d}}$ Values are $\beta(95 \% \mathrm{Cl})$.

${ }^{\mathrm{e}} P$ value $<.001$ ( $\alpha=.003$ after Bonferroni adjustment for multiple comparisons).

${ }^{\mathrm{f}}$ Values are RR $(95 \% \mathrm{Cl})$.

${ }^{\mathrm{g}} P$ value $<.003$ ( $\alpha=.003$ after Bonferroni adjustment for multiple comparisons).

${ }^{\mathrm{h}} P$ value $>.003$ ( $\alpha=.003$ after Bonferroni adjustment for multiple comparisons). 